\title{
Gender Traits and Cognitive Appraisal in Young Adults: The Mediating Role of Locus of Control
}

\author{
Oriane Sarrasin • Eric Mayor • Klea Faniko
}

Published online: 24 December 2013

(C) Springer Science+Business Media New York 2013

\begin{abstract}
The present study examined the relationships between masculine and feminine traits, measured using the Bem Sex-Role Inventory (BSRI), and the way young adults appraise events (i.e., as threats or as challenges). We hypothesized that the locus of control (LOC) - i.e., individuals' perceived control over the events that affect them-mediated these relationships. We tested these assumptions on two student samples from the French-speaking part of Switzerland $(N=123$ and $N=504)$. Regression analyses demonstrated that, as expected, agentic masculine traits were positively related to challenge appraisals, and negatively to threat appraisals. LOC mediated these relationships, but most strongly among female participants. A different pattern was found for femininity. Feminine traits were positively related to increased challenge appraisals, but only in female participants of Sample 2. They were also related, in some cases, to increased threat appraisals. Furthermore, in line with previous research, LOC did not mediate the relationship between feminine traits and cognitive appraisal. Overall, the present results confirm that masculine and feminine stereotypical traits differ in their consequences for the way young adults appraise events in their everyday life.
\end{abstract}

Keywords Gender traits · BSRI - Cognitive appraisal of stress $\cdot$ Locus of control

O. Sarrasin $(\square)$

Department of Social Psychology, Faculty of Social and Political Sciences, University of Lausanne, CH-1015 Lausanne, Switzerland e-mail: oriane.sarrasin@gmail.com

\section{E. Mayor}

Institute of Work and Organizational Psychology, University of Neuchâtel, Neuchâtel CH-2000, Switzerland

e-mail: eric.mayor@unine.ch

K. Faniko

Faculty of Psychology and Educational Sciences, University of Geneva, Geneva 4 CH-1211, Switzerland

e-mail: klea.faniko@unige.ch

\section{Introduction}

Stereotypical gender traits have been repeatedly shown to explain how men and women react to adversity in their everyday life, such as the levels of depression they report (in Hong Kong university students, Lam and McBride-Chang 2007) or the strategies they mobilize when faced with stressful events (in Chinese university students, Cheng 2005). Indeed, numerous studies have been dedicated to the understanding of the impact of masculine and feminine traits on individuals' reactions to stressors (in Sex Roles: in US undergraduates, Stake 2000; in US college students, Wang 2007; and in student and non-student Australian adults, Woodhill and Samuels 2003). With the exception of a few studies on female managers and students (e.g., in Canada, Long et al. 1992; in the US, Tomaka et al. 1999), far less research has been devoted to understanding how masculine and feminine traits are related to the way individuals generally tend to appraise events (i.e., as challenges vs. as threats). It is however crucial to study such relationships, as challenge and threat appraisals have considerable consequences for the way individuals react to stressors (e.g., in undergraduates, Skinner and Brewer 2002). The present study seeks to fill this gap. However, since the expression of masculine and feminine traits is known to differ greatly across cohorts (in the US, Twenge 1997), educational levels (in Spain, Calvo-Salguero et al. 2008), and contexts (in 29 countries, Moya et al. 2005), this cannot be done without carefully taking into account both the population and the context under study.

With these considerations in mind, we used regression analysis to examine the relationship between gender traits and cognitive appraisals in two student samples from the French-speaking region of Switzerland. On the one hand, compared with other Western countries, Switzerland was quite late in reaching gender equality in terms of rights (e.g., women obtained the right to vote in 1971). Moreover, the division of 
both domestic tasks (Branger et al. 2003) and of labor (e.g., many women work only part time) is still predominantly traditional (Losa and Origoni 2005). These traditional gender roles may be reflected in young adults' attitudes. For instance, students living in the French-speaking part of Switzerland appear to have higher levels of modern forms of sexism (Martínez et al. 2010) than students from neighboring countries (e.g., in France, Guimond et al. 2003). Altogether, it seems that in Switzerland gender attitudes and practices are more traditional than in other Western European countries. Because many gender-differentiated attitudes and behaviors are more pronounced in traditional contexts (for a review see Else-Quest and Grabe 2012), the impact of stereotypical gender traits is likely to be most apparent in Switzerland. For these reasons, we expected that, in students living in the French-speaking part of Switzerland, masculine traits would relate to both increased challenge appraisals and decreased threat appraisals, while we expected the reverse situation for feminine traits.

On the other hand, agency - a stereotypically masculine trait-is a valued characteristic in Switzerland (for instance, Switzerland scores high on Hofstede's masculinity dimension; Hofstede 2001). This may explain why, as in many other countries (e.g., in Canada, Yaremko and Lawson 2007; in Turkey, Özkan and Lajunen 2005; in Sweden, Snellman et al. 2009), female students living in Switzerland valued masculine traits as much as male students did, but scored higher in feminine traits (Moya et al. 2005). A similar pattern was found in the present study. However, while male and female students may differ in their expression of masculine and feminine traits, we assumed, and showed, that gender traits were related to cognitive appraisals in a rather similar way in both male and female young adults.

\section{Gender Traits}

Psychological gender can be understood as the personality characteristics or behaviors stereotypically considered as more appropriate for one gender than for the other (Ridgeway 2011). Masculinity is traditionally associated with masteryand task-oriented traits such as dominance, instrumentality, and agency, while femininity is associated with other-oriented traits such as nurturance, communion, and expressiveness (Bem 1975). While masculinity and femininity were traditionally depicted as two ends of the same continuum (see, for a history of research on gender traits, Biernat and Deaux 2012), they in fact constitute two separate dimensions (Bem 1974). Thus, individuals can be predominantly masculine or feminine, but they can also possess each type of trait to a similar extent (Bem 1974, 1981).

Generally, men tend to be more masculine (e.g., assertive) than women, and women more feminine (e.g., warm) than men (meta-analysis conducted on student and non-student samples from various countries; Feingold 1994; secondary analyses on student and adult samples from 26 cultures; Costa et al. 2001). However, in a meta-analysis of studies conducted on US undergraduates from the 1970s to the 1990s, gender differences in gender traits were found to decrease (Twenge 1997). Female undergraduates have increasingly expressed masculine traits in the last decades, probably because women have increasingly adopted traditionally masculine roles (e.g., being in full-time employment), or because masculine agentic characteristics are more valued than feminine characteristics in Western societies (Twenge 2009). The reverse situation, that is male undergraduates adopting feminine traits, has not been observed (Twenge 1997). While changes in gender traits were formally studied in US samples only, the pattern observed by Twenge in the late 1990s is clearly visible in results from recent studies conducted among young adults in different contexts. Indeed, in various cultural settings, male and female students were found not to differ or differ little in their expression of masculine traits, while female students expressed feminine traits to a greater extent than male students (in Canada, Yaremko and Lawson 2007; in Turkey, Özkan and Lajunen 2005; in Sweden, Snellman et al. 2009). Finally, note that these results may be due to the participants' cohorts, but also to their educational level, as more highly educated individuals tend to express less pronounced stereotypical gender traits than less educated individuals (in Spanish employees, Calvo-Salguero et al. 2008).

\section{Gender Traits and Reactions to Stressors}

\section{Cognitive Appraisal and Coping Strategies}

According to the transactional theory of stress (Lazarus 1966; Lazarus and Folkman 1984), when faced with a stressor (e.g., a new situation), individuals evaluate the potential consequences for their well-being. This evaluation, referred to as primary appraisal (Lazarus and Folkman 1984), is usually divided into two types: threat and challenge appraisals. Threat appraisals refer to when individuals perceive that the demands of the situation exceed the resources they can provide, while challenge appraisals refer to situations individuals assess as manageable (Lazarus and Folkman 1984; Tomaka et al. 1999). Primary appraisals can describe reactions to a given stressor, but individuals are also known to adopt consistently one type of cognitive appraisal to a greater extent than the other (Lazarus 1991; Roesch and Rowley 2005).

In a secondary appraisal, individuals evaluate the available options, namely what can be done to face the stressor (Lazarus 2006). Secondary appraisals determine which strategies the individuals are going to engage in order to cope with the consequences of the stressor (coping strategies). Stereotypical gender traits have proved to be extremely useful for understanding individual differences in coping strategies. 
On the one hand, some authors have argued that masculine agentic traits are crucial for predicting well-being (meta-analyses: both on student and non-student non-clinical samples, Bassoff and Glass 1982; Whitley 1985). This may be because masculine traits correspond better to cultural demands in Western societies (e.g., US undergraduates evaluated masculine traits as being more desirable than feminine traits, Auster and Ohm 2000; see also Twenge 2009) or because they are associated with more efficient coping strategies than feminine traits (e.g., in Anglo-Australian and Chinese adults living in Australia, Leung and Moore 2003). On the other hand, other authors have relied on the sex role adaptability theory (Bem 1975) to show that, by possessing a broader array of potential responses, individuals with strong masculine and feminine traits are most likely to cope efficiently with stressors (e.g., in Chinese university students, Cheng 2005).

Thus, the relationship between gender traits and strategies used to cope with stressors has been extensively studied. In contrast, the extent to which masculine and feminine traits influence the way men and women generally appraise situations in their everyday life, that is as threats versus challenges, is yet to be examined. Such an examination is much needed, as primary (or cognitive) appraisals have been shown to determine well-being outcomes in both student and non-student samples (Skinner and Brewer 2002). For instance, threat appraisals were related to negative outcomes such as anxiety and negative emotions (Sarason and Sarason 1990), whereas challenge appraisals were found to predict positive outcomes such as stable self-esteem (in US undergraduates, Seery et al. 2004) and lower subjective stress (in US college students, Tomaka et al. 1993). Finally, note that the array of events that may potentially affect individuals' life is extremely broad. For this reason, it is crucial to compare individuals who experience similar stressful events in their everyday life. For this reason, the present study examines cognitive appraisals in students, who are likely to experience, for instance, stress related to academic performances and financial insecurities.

\section{Gender Traits and Cognitive Appraisal}

As attributes such as competition and seeking success are key in traits such as agency, assertiveness, and dominance (see Twenge 2009), individuals with strong masculine traits are likely to evaluate the situations they encounter as being manageable, and not as threatening. In line with this assumption, women with masculine traits were found to evaluate situations as being more challenging (female Canadian managers, Long et al. 1992; female US students, Tomaka et al. 1999), and to report less anxiety (a phenomenon related to threat appraisal, Sarason and Sarason 1990) than women who do not possess these traits. Because these studies did not include male participants, we can only speculate on the impact of masculine traits in male students. While previous research suggests that male students are on average more likely to perceive events as more challenging than female students (e.g., Sigmon et al. 1995), there is no reason to expect masculine traits to impact cognitive appraisals differently in male than in female students. Thus, we expect that, in male and female young adults, the expression of masculine traits generally increases challenge appraisals, and decreases threat appraisals.

While female students and adolescents were found to evaluate stressful events as being more unpleasant than their male counterparts (in Australia, Mak et al. 2004; Sigmon et al. 1995), the impact of feminine traits on cognitive appraisals, on the other hand, has never been directly tested. However, we have two reasons to expect femininity to relate to increased threat appraisals and decreased challenge appraisals. First, femininity is characterized by the expression of feelings and emotions. Thus, individuals with feminine traits may more readily acknowledge that the situation exceeds what they can provide (Bronstein et al. 1996). Second, femininity is also defined by the tendency to take care of, and to feel concern for others. Because they perceive that others depend upon them (Snedker 2006), feminine individuals may perceive situations as potentially threatening not only for the people they care for, but also for themselves. For these reasons, we expect that the expression of feminine traits generally would decrease challenge appraisals and increase threat appraisals. Again, there is no reason to expect feminine traits to impact cognitive appraisals differently in young female and male adults.

\section{The Mediating Role of Locus of Control}

To further examine mechanisms linking gender traits to cognitive appraisal, we included the concept of locus of control into our consideration. Locus of control (LOC) is defined as the dispositional expectancies regarding the source of control of events (Rotter 1966). Individuals with an internal LOC perceive that they have control over events, while individuals with an external LOC do not report having control over events, which are seen as being influenced by external forces. While LOC was initially conceptualized as being internal vs. being external (Rotter 1966), Levenson $(1974,1981)$ postulated two perceived sources of external control: powerful others and chance (or fate, bad luck). While the first dimension implies that other humans - those in powerful positions - are in control, the second refers to a belief in the random nature of the world.

Defined by some authors (e.g., Lefcourt 1982) as personal mastery, internal LOC is likely to be expressed by individuals with agentic and instrumental traits. Unsurprisingly, individuals with masculine traits have been consistently shown to score high on internal LOC (US non-student adults, Kapalka and Lachenmeyer 1988; US mental health workers, Williams and Stout 1985; US student adults, Gianakos 2002). This may explain why earlier studies found 
men to attribute more frequently the causes of events to internal factors than women (for a review see Sherman et al. 1997), while more recent studies revealed no or less pronounced gender differences (e.g., in US undergraduates, Lengua and Stormshak 2000). When it comes to reactions to stressors, internal LOC was found to relate to lower levels of stress (in US salespeople, Judge et al. 2002), positive perceptions of stress (in newly hired juniors in accounting firms, Bernardi 1997), and lower levels of threat appraisals (in medical US students, Vitaliano et al. 1987). Conversely, a high internal/low external LOC was related to more problem-focused (i.e., instrumental) coping strategies (metaanalysis, mostly on US samples, by $\mathrm{Ng}$ et al. 2006). Finally, Roddenberry and Renk (2010) found that, in US undergraduate students, adopting an external LOC (attributing the causes of events to powerful others and chance) predicted high levels of stress. Overall, individuals with masculine traits appear to have a high internal/low external LOC, which, in turn, can be expected to result in perceptions of events as challenges and not as threats.

In contrast to agency, control and, conversely, lack of control, do not appear to be relevant dimensions underlying the content of feminine traits, mostly defined in terms of interpersonal relationships or behaviors (e.g., taking care of or being kind toward other people). This may explain why the impact of feminine traits on LOC is less clear-cut; while some results pointed to a positive relationship between femininity and external LOC (e.g., in Israeli adults, Moore 2007), other studies reported no differences (e.g., Kapalka and Lachenmeyer 1988; Lengua and Stormshak 2000). As discussed by Kapalka and Lachenmeyer (1988), "it is not clear whether this [the relation between femininity and externality] is solely a function of low scores on the instrumental cluster, or whether the dimension of expressiveness is negatively related to locus of control" (p. 418). Likewise, while US children and undergraduates seem to increasingly attribute the causes of events to external forces (meta-analysis by Twenge et al. 2004), studies differed on the issue of whether men and women generally differ in their external LOC (Christopher et al. 2009; Sherman et al. 1997). Overall, there is no firm reason to expect LOC to mediate the relationship between feminine traits and primary cognitive appraisal.

\section{Hypotheses}

We hypothesize that, among both male and female students living in the French-speaking region of Switzerland, masculine traits relate positively to high internal/low external LOC (H1) and challenge cognitive appraisals (H2), and negatively to threat cognitive appraisals (H3). Because we also expect LOC to relate positively to challenge appraisal $(\mathrm{H} 4)$ and negatively to threat appraisals (H5), LOC is expected to mediate the relationships between masculine traits and challenge appraisals (H6) and between masculine traits and threat appraisals (H7). We hypothesize that feminine traits relate negatively to challenge cognitive appraisals (H8), and positively to threat cognitive appraisals (H9). However, in contrast to the prevailing patterns regarding masculine traits, previous research gives us no reason to expect LOC to mediate these relationships. Thus, we make no prediction regarding a feminine traits-LOC-cognitive appraisals relationship. Finally, the hypothesized mechanisms (i.e., described in H1 to H9) are assumed to occur in both male and female students. However, based on previous research, male students may score higher in challenge appraisals, and female students higher in feminine traits and threat appraisals.

\section{Method}

Participants

\section{Sample 1}

The data of Sample 1 were drawn from a larger convenience online sample targeting the French-speaking region of Switzerland $(N=322)$, in which 144 individuals reported studying. Participants were recruited with the snowball sampling method: The two first authors invited acquaintances both to fill in the online questionnaire and forward the link. We selected participants corresponding to the typical student age group (i.e., maximum 30 years old; see Table 1). Among the 123 remaining participants ( 35 self-rated men, and 88 selfrated women), a majority reported having a job (63 women and $22 \mathrm{men}$ ), and 78 participants (58 women and $20 \mathrm{men}$ ) did not live with their parent(s). No information was provided on their year or field of study. Finally, 75 female and 34 male participants reported having Swiss citizenship.

\section{Sample 2}

Participants of Sample $2(N=525)$ were students from two Swiss French universities who filled in a paper-and-pencil version of the questionnaire during lectures, or were recruited in the university cafeteria. Data from participants who only partially filled in the questionnaire $(N=13)$ or who were older than $30(N=8)$ were discarded. Among the 504 remaining participants ( 229 self-rated men and 275 self-rated women; for information on their age, see Table 1), half reported having a job (141 women and 108 men) and a minority (102 women and $57 \mathrm{men}$ ) did not live with their parent(s). Participants (mostly in their first year of study, $N=412$ ) came from various academic fields: economics ( 82 women and 98 men), international relations ( 73 women and 44 men), political science (32 women and $24 \mathrm{men}$ ), geography (17 women and $14 \mathrm{men}$ ), or others (63 women and 37 men). Twenty students did not 
Table 1 Means and standard deviations of age, gender traits, locus of control, and cognitive appraisals

\begin{tabular}{|c|c|c|c|c|c|c|c|c|}
\hline & \multicolumn{3}{|l|}{ Sample 1} & \multicolumn{3}{|l|}{ Sample 2} & \multicolumn{2}{|l|}{ All } \\
\hline & $\operatorname{Men}(N=35)$ & Women $(N=88)$ & All & $\operatorname{Men}(N=229)$ & Women $(N=275)$ & All & $\operatorname{Men}(N=264)$ & Women $(N=363)$ \\
\hline \multicolumn{9}{|l|}{ Age } \\
\hline $\mathrm{M}(\mathrm{SD})$ & $23.77(4.04)$ & $24.20(3.04)$ & $24.08(3.35)$ & $20.62(1.93)$ & $20.56(2.09)$ & $20.61(2.00)$ & $21.04(2.55)$ & $21.47(2.80)$ \\
\hline Range & $18-30$ & $18-30$ & & $18-28$ & $17-30$ & & & \\
\hline \multicolumn{9}{|l|}{ Masculinity } \\
\hline $\mathrm{M}(\mathrm{SD})$ & $4.50(.71)$ & $4.42(.87)$ & $4.44^{\mathrm{a}}(.83)$ & $4.82(.74)$ & $4.78(.70)$ & $4.80^{\mathrm{a}}(.72)$ & $4.78(.74)$ & $4.69(.76)$ \\
\hline Range & $3.10-6.10$ & $1.00-6.70$ & & $2.30-6.40$ & $3.00-6.60$ & & & \\
\hline \multicolumn{9}{|l|}{ Femininity } \\
\hline $\mathrm{M}(\mathrm{SD})$ & $5.26(.70)$ & $5.45(.87)$ & $5.40^{\mathrm{b}}(.83)$ & $4.98(.80)$ & $5.18(.79)$ & $5.09^{\mathrm{b}}(.80)$ & $5.02^{\mathrm{d}}(.79)$ & $5.24^{\mathrm{d}}(.82)$ \\
\hline Range & $4.00-6.78$ & $1.00-7.00$ & & $2.11-6.89$ & $2.33-7.00$ & & & \\
\hline \multicolumn{9}{|l|}{ LOC } \\
\hline $\mathrm{M}(\mathrm{SD})$ & $4.49(.57)$ & $4.43(.67)$ & $4.44^{\mathrm{c}}(.64)$ & $4.17(.52)$ & $4.21(.51)$ & $4.19^{\mathrm{c}}(.52)$ & $4.22(.54)$ & $4.26(.56)$ \\
\hline Range & $3.33-5.56$ & $2.67-6.00$ & & $2.91-5.55$ & $3.00-5.77$ & & & \\
\hline \multicolumn{9}{|c|}{ CA Challenge } \\
\hline $\mathrm{M}(\mathrm{SD})$ & $4.46(.61)$ & $4.23(.74)$ & $4.30(.71)$ & $4.40(.63)$ & $4.26(.73)$ & $4.32(.69)$ & $4.40^{\mathrm{e}}(.63)$ & $4.25^{\mathrm{e}}(.73)$ \\
\hline Range & $2.88-5.50$ & $1.00-5.89$ & & $2.25-5.75$ & $1.75-5.88$ & & & \\
\hline \multicolumn{9}{|l|}{ CA Threat } \\
\hline $\mathrm{M}(\mathrm{SD})$ & $3.21(1.04)$ & $3.71(1.15)$ & $3.57(1.14)$ & $3.36(.94)$ & $3.51(1.10)$ & $3.45(1.03)$ & $3.34^{\mathrm{f}}(.95)$ & $3.56^{\mathrm{f}}(1.11)$ \\
\hline Range & $1.22-5.78$ & $1.75-6.00$ & & $1.00-5.78$ & $1.00-6.00$ & & & \\
\hline
\end{tabular}

High scores in LOC indicate a high internal/low external LOC

Means sharing a subscript differ significantly from one another

provide information on their field of study. Finally, 198 female and 164 male participants reported having Swiss citizenship.

\section{Measures}

\section{Gender Traits}

Gender traits were measured using the short Bem SexRole Inventory (Bem 1974). We used a translation by Rogé 1992 (in Bouvard 2009). Participants indicated to what extent (from $1=$ never to $7=$ always) 20 characteristics (10 masculine and 10 feminine) described them. Examples are assertive (plein/e d'assurance) and independent (indépedant/e) for the masculine traits, and warm (chaleureux/euse) and affectionate (affectueux/se) for the feminine traits. In both samples, we retained 19 characteristics for the analysis because one translation (i.e., for sympathetic) proposed by Rogé and used in Sample 1, although not incorrect, differed considerably from other existing French translations (e.g., the version for adolescents by Fontayne et al. 2000). Indeed, sympathetic can describe either a nice, kind person or a person who feels compassion for others. While other translations seem to favor the latter meaning, Rogé translated sympathetic as "sympathique" (i.e., nice).
Although the BSRI was conceived to measure two dimensions, many studies revealed distinct masculine and feminine subdimensions (e.g., in UK students, Colley et al. 2009). To examine the structure of gender traits, we conducted exploratory factor analyses (EFA; principal components, varimax rotation) on data of male and female participants separately. In each sample, the number of factors was evaluated with a scree test (Cattell, 1966). Across all samples, results revealed two major dimensions, corresponding to the original feminine and masculine dimensions (explained variance, Sample $1_{\text {male }}$ : $26.47 \%$ and $18.62 \%$; Sample $1_{\text {female: }} 37.87 \%$ and $16.61 \%$; Sample $2_{\text {male: }} 24.14 \%$ and $18.54 \%$; Sample $2_{\text {female: }} 20.96 \%$ and $18.28 \%$ ). All loadings were superior to .30 (Costello and Osborne 2005; see Colley et al. 2009 for an example with the BSRI), with the exceptions of aggressive in Sample $1_{\text {male }}$ (loading=.26), independent in Sample 2 male (loading=.22), and forceful in Sample $2_{\text {female }}$ (loading=.28). Acceptable reliability was reached in all samples (masculine traits, Sample $1_{\text {male: }}$ : $\alpha=.80$; Sample $1_{\text {female: }} \alpha=.87$; Sample $2_{\text {male }}: \alpha=.80$; Sample $2_{\text {female }}: \alpha=.79$; feminine traits, Sample $1_{\text {male }}: \alpha=.85$; Sample $1_{\text {female: }} \alpha=.90$; Sample 2 male: $\alpha=.84$; Sample $2_{\text {female }}: \alpha=.79$ ).

\section{Locus of Control}

LOC was measured using the Internal, Powerful Others, and Chance Scale (IPC; eight items per subdimension, Levenson 
1974). As we did not have specific hypotheses regarding internal vs. external LOC, we decided to use one overall score of high internal/low external LOC (high scores indicated internal attributions). We used a version translated by Loas et al. (1994) and validated by Rossier et al. (2002) on student and non-student Swiss French samples. Participants were invited to give their agreement (from 1=totally disagree to $6=$ totally agree ) with a list of affirmations. Sample items are: "I am usually able to protect my personal interests" (En général, je suis capable de protéger mes intérêts personnels), and "I feel like what happens in my life is mostly determined by powerful people" (J'ai le sentiment que ce qui arrive dans ma vie est principalement décidé par les gens puissants; reversed item).

In Sample 1, we followed Wagner-Egger and Bangerter's (2008) procedure (additional information given to the authors by Wagner-Egger and Bangerter), and selected the three items in each subdimension that had the highest loadings in the Rossier et al. study. EFA were performed on data of male and female participants. For both, the scree test revealed one main dimension (explained variance, Sample $1_{\text {male }}: 31.29 \%$; Sample $1_{\text {female }}: 38.19 \%$ ). All loadings were superior to .30 , with the exception of one chance item in the male sample (loading=.03). To have a comparable scale, we decided to keep this item (note that regression analyses similar to those performed in the Result section but with a 8-item LOC score yielded similar findings). The resulting 9-item scale had an acceptable reliability for both male $(\alpha=.66)$ and female $(\alpha=.77)$ participants.

In Sample 2, the entire scale was administered. First, we discarded two internal items ("Whether or not I get into a car accident depends mostly on how good a driver I am," and "How many friends I have depends on how nice a person I am"), which did not correlate significantly with the other internal items (these items are known to perform poorly; see Wilkinson 2007). Then, we conducted EFA (principal components, varimax rotation) on the 22 remaining items. The scree test revealed one main dimension for both male and female participants (Sample 2 male: $21.96 \%$; Sample $2_{\text {female: }}$ : $18.19 \%$ ). While most loadings were superior to .30 , they appeared to be slightly lower for the items tapping internal LOC. The resulting 22-item scale had an acceptable reliability for male $(\alpha=.78)$ and female $(\alpha=.74)$ participants.

\section{Cognitive Appraisal}

Cognitive appraisal was measured using the Cognitive Appraisal Scale (Skinner and Brewer 2002). We use the version translated and validated by Berjot and GiraultLidvan (2009) on French university students. Participants were invited to give their agreement (from $1=$ totally disagree to $6=$ totally agree) with a list of 18 affirmations. Sample items are: "In general I look forward to the rewards and benefits of success" (J'ai tendance à rechercher les récompenses et les retombées de la réussite; challenge), and "I worry that I will say or do the wrong things" (Je crains toujours de dire ou de faire les choses de travers; threat). Following recommendations by Berjot and Girault-Lidvan (2009), we first discarded the "I often think about what it would be like if I do very well" item, because it was found in the validation study to load on the threat dimension instead of on the challenge dimension. Second, we reversed the score for the "I feel like a failure" item and incorporated it into the challenge dimension.

EFA (principal components, varimax rotation) on the resulting items confirmed, through scree tests, the presence of two major dimensions, corresponding to the threat and challenge original dimensions (explained variance, Sample $1_{\text {male }}: 35.08 \%$ and $19.45 \%$; Sample $1_{\text {female }}: 36.56 \%$ and $18.83 \%$; Sample $2_{\text {male }}: 28.72 \%$ and $16.18 \%$; Sample $2_{\text {female: }}$ : $34.60 \%$ and $16.58 \%$ ). All loadings were superior to .30 , with the exception of one challenge item for male participants of Sample 1 (loading $=.23$ ). The final challenge scale was composed of eight items (Sample $1_{\text {male }}: \alpha=.70$; Sample $1_{\text {female: }}$ : $\alpha=.77$; Sample $2_{\text {male }}: \alpha=.66$; Sample $2_{\text {female }}: \alpha=.72$ ), while the final threat scale was composed of nine items (Sample $1_{\text {male }}: \alpha=.91$; Sample $1_{\text {female }}: \alpha=.92$; Sample $2_{\text {male }}: \alpha=.87$; Sample $2_{\text {female }}: \alpha=.91$ ).

\section{Results}

\section{MANOVA}

The means and standard deviations of all measures are presented in Table 1. We performed a Multivariate Analysis of Variance (MANOVA) on masculine and feminine traits, LOC, and threat and challenge appraisals with gender, sample, and their interaction as independent variables. Results revealed effects of gender, $F(5,619)=$ $3.69, p=.003$, Wilks's $\Lambda=.97)$ and sample, $F(5,619)=$ $12.51, p<.001$, Wilks's $\Lambda=.91)$. In contrast, the gender X sample interaction yielded no significant effect $(p=.77)$. Differences between male and female participants, as well as between Sample 1 and Sample 2, were examined with ANOVAs performed on each dependent variable separately. In line with previous research, female participants scored higher in feminine traits, $F(1,623)=4.91, p=.03$ ) and threat appraisals than male participants, $F(1,623)=$ 7.94, $p=.005$; for means, see Table 1). While there were no significant gender differences in masculine traits and LOC, male participants scored higher in challenge appraisals than female participants, $F(1,623)=5.77$, $p=.02)$. Participants of Sample 1 were more feminine, $F(1,623)=10.24, p=.001)$ and less masculine, $F(1,623)=$ $17.45, p<.001)$ than participants of Sample 2. While there 
were no significant differences in cognitive appraisals between the two samples, participants of Sample 1 scored higher in high internal/low external LOC than participants of Sample 2, but as the LOC score of Sample 1 comprised of fewer items than the score of Sample 2, interpretations would be at best speculative.

\section{Regression Analyses}

To test whether LOC mediated the relationship between gender traits and cognitive appraisals, multiple regressions were conducted with Stata 12 (StataCorp 2011). Analyses were performed on male and female participants of each sample separately. In all cases, all models were controlled for age, not living with parents, and having a job (the latter two being potential sources of financial insecurities and stress in students). All continuous predictors were centered around the grand mean.

A first series of models examined whether masculine and feminine traits were related to the potential mediating mechanism, i.e., high internal/low external LOC. A second and third series of models examined the factors predicting respectively challenge and threat appraisals. For each, the first step involved entering masculine and feminine traits, as well as the control variables, as predictors. Then, high internal/low external LOC was entered in the second step. These final models are presented in Tables 2 and 3. Variance Inflation Factors ranged from 1.08 to 2.40 , indicating that multicollinearity was not an issue (see O'Brien 2007).

To test whether LOC (mediator: Me) significantly mediated the relationship between gender traits (independent variables: IVs) and cognitive appraisal (dependent variables: DVs), we relied on bootstrapped estimations (1000 repetitions) of indirect paths provided by the sgmediation Stata command. Based on the multiplication of the IV-Me and Me-DV coefficients, the indirect path is in most cases equivalent to the reduction in the direct effect (IV-DV) observed when the mediator is introduced (as estimated in the traditional method by Baron and Kenny 1986; Preacher and
Hayes 2004). We relied on bootstrapped estimates, because they provide more accurate results, especially when one relies on small samples (Preacher and Hayes 2004) such as our Sample 1.

\section{Sample 1}

First, in the models predicting LOC, masculine traits were positively related to a high internal/low external LOC for both male and female participants $\left(\mathrm{H} 1 ; b_{\text {male }}=.32, S E=.14\right.$, $\left.p=.04 ; b_{\text {female }}=.27, S E=.09, p=.002\right)$. In contrast, feminine traits were not significantly related to LOC $\left(b_{\text {male }}=\right.$ $\left.-.07, S E=.14, p=.61 ; b_{\text {female }}=-.03, S E=.09, p=.77\right)$.

Second, masculine traits were found to relate positively to challenge appraisals $\left(\mathrm{H} 2 ; b_{\text {male }}=.49, S E=.13, p=.001\right.$; $\left.b_{\text {female }}=.36, S E=.09, p<.001\right)$. Not supporting H8, feminine traits had no significant impact on challenge appraisals $\left(b_{\text {male }}=.16, S E=.13, p=.21 ; b_{\text {female }}=-.11, S E=.10\right.$, $p=.23)$. LOC was entered in a second step: It has a significant impact on challenge appraisals (H4; see the two left panels of Table 2). Bootstrapped indirect effect confirmed the mediation, but only for female participants $\left(b_{\text {male }}=.12, S E=.07\right.$, $p=.12 ; 95 \%$ CI: -.03 to $.26 ; b_{\text {female }}=.10, S E=.05, p=.04$; 95\%CI: .00 to .19): As expected (H6), masculine traits were positively related to challenge appraisals through LOC.

Third, in models predicting threat appraisals, for female participants, masculine traits were negatively related to $(\mathrm{H} 3$ : $b_{\text {female }}=-.48, S E=.15, p=.002$ ), and feminine traits positively related to threat appraisals (H9: $b_{\text {female }}=.45, S E=.15$, $p=.004)$. A similar pattern was observed for male participants, but the effects did not reach significance (masculine traits: $b_{\text {male }}=-.42, S E=.27, p=.13$; feminine traits: $b_{\text {male }}=.39, S E=.27, p=.15$ ). Consequently, the mediating role of LOC was examined for female participants only. As shown in Table 3, a high internal/low external LOC was significantly related to reduced threat appraisals (H5). Bootstrapped indirect effect showed that LOC significantly mediated the relationship between masculine traits and
Table 2 Results of multiple regressions predicting challenge appraisals (final models), by sample and gender

${ }^{* * *} p<.001,{ }^{* *} p<.01,{ }^{*} p<.05$, ${ }^{\#} p<.10$

\begin{tabular}{|c|c|c|c|c|c|c|c|c|}
\hline & \multicolumn{2}{|c|}{ Sample 1 men } & \multicolumn{2}{|c|}{ Sample 1 women } & \multicolumn{2}{|c|}{ Sample 2 men } & \multicolumn{2}{|c|}{ Sample 2 women } \\
\hline & $\mathrm{B}$ & SE & $\mathrm{B}$ & SE & $\mathrm{B}$ & SE & $\mathrm{B}$ & SE \\
\hline Constant & 4.51 & $(.18)^{* * *}$ & 4.10 & $(.17)^{* * *}$ & 4.38 & $(.06)^{* * *}$ & 4.23 & $(.07)^{* * *}$ \\
\hline Masculinity & .38 & $(.13)^{* *}$ & .27 & $(.09)^{* *}$ & .28 & $(.05)^{* * *}$ & .31 & $(.06)^{* * *}$ \\
\hline Femininity & .19 & $(.12)$ & -.11 & $(.09)$ & .02 & $(.05)$ & .10 & $(.05)^{\#}$ \\
\hline LOC & .36 & $(.15)^{*}$ & .36 & $(.11)^{* *}$ & .31 & $(.07)^{* * *}$ & .39 & $(.08)^{* * *}$ \\
\hline Age & -.02 & $(.03)$ & -.04 & $(.03)$ & -.01 & $(.02)$ & -.02 & $(.02)$ \\
\hline Not with parents & -.06 & $(.25)$ & .02 & $(.18)$ & .09 & $(.09)$ & .02 & $(.09)$ \\
\hline Has a job & -.03 & (.19) & .17 & $(.17)$ & -.01 & $(.08)$ & .04 & $(.09)$ \\
\hline $\mathrm{R}^{2}$ & \multicolumn{2}{|c|}{$51.35 \%$} & \multicolumn{2}{|c|}{$28.19 \%$} & \multicolumn{2}{|c|}{$21.13 \%$} & \multicolumn{2}{|c|}{$22.35 \%$} \\
\hline
\end{tabular}


Table 3 Results of multiple regressions predicting threat appraisals (final models), by sample and gender

${ }^{* * *} p<.001,{ }^{* *} p<.01,{ }^{*} p<.05$, ${ }^{\#} p<.10$

\begin{tabular}{|c|c|c|c|c|c|c|c|c|}
\hline & \multicolumn{2}{|c|}{ Sample 1 men } & \multicolumn{2}{|c|}{ Sample 1 women } & \multicolumn{2}{|c|}{ Sample 2 men } & \multicolumn{2}{|c|}{ Sample 2 women } \\
\hline & $\mathrm{B}$ & SE & $\mathrm{B}$ & SE & $\mathrm{B}$ & SE & $\mathrm{B}$ & SE \\
\hline Constant & 3.09 & $(.40)^{* * *}$ & 3.40 & $(.26)^{* * *}$ & 3.31 & $(.09)^{* * *}$ & 3.48 & $(.11)^{* * *}$ \\
\hline Masculinity & -.23 & $(.28)$ & -.27 & $(.14)^{\#}$ & -.19 & $(.08)^{*}$ & -.36 & $(.09)^{* * *}$ \\
\hline Femininity & .35 & $(.26)$ & .43 & $(.14)^{* *}$ & .17 & $(.08)^{*}$ & .08 & $(.08)$ \\
\hline LOC & -.60 & $(.33)^{\#}$ & -.78 & $(.17)^{* * *}$ & -.54 & $(.11)^{* * *}$ & -.55 & $(.12)^{* * *}$ \\
\hline Age & .00 & $(.07)$ & -.05 & $(.04)$ & -.04 & $(.03)$ & -.04 & $(.04)$ \\
\hline Not with parents & -.05 & $(.53)$ & .14 & $(.27)$ & .06 & $(.14)$ & .15 & $(.14)$ \\
\hline Has a job & .25 & $(.41)$ & .31 & $(.25)$ & .10 & $(.12)$ & -.05 & $(.14)$ \\
\hline $\mathrm{R}^{2}$ & \multicolumn{2}{|c|}{$22.74 \%$} & \multicolumn{2}{|c|}{$32.98 \%$} & \multicolumn{2}{|c|}{$13.77 \%$} & \multicolumn{2}{|c|}{$14.48 \%$} \\
\hline
\end{tabular}

reduced threat appraisals $(\mathrm{H} 7: b=-.21, S E=.08, p=.007$; 95\% CI: -.37 to -.06$)$.

Finally, for both male and female participants, any of the control variables had a significant impact on LOC, challenge appraisals, and threat appraisals.

\section{Sample 2}

First, in the models predicting LOC, masculine traits were positively related to a high internal/low external LOC for both male and female participants $\left(\mathrm{H} 1: b_{\text {male }}=.10, S E=.05\right.$, $\left.p=.04 ; b_{\text {female }}=.12, S E=.04, p=.009\right)$. In contrast, feminine traits were not significantly related to LOC $\left(b_{\text {male }}=.05, S E=.04, p=.24 ; b_{\text {female }}=.02, S E=.04\right.$, $p=.56)$.

Second, masculine traits were significantly and positively related to challenge appraisals $\left(\mathrm{H} 2: b_{\text {male }}=.31, S E=.05, p\right.$ $\left.<.001 ; b_{\text {female }}=.36, S E=.06, p<.001\right)$. Contrary to our expectations (H8), feminine traits were also positively related to challenge appraisals, but for female participants only $\left(b_{\text {male }}=.04, S E=.05, p=.45 ; b_{\text {female }}=.11, S E=.05, p=.05\right)$. When LOC was entered in the model, it was significantly related to increased challenge appraisals in both male and female participants (H4: see the two right panels of Table 2). Bootstrapped indirect effect confirmed that LOC mediated the relationship between masculine traits and challenge appraisals for female participants (H6: $b_{\text {female }}=.05, S E=.02, p=.04 ; 95 \% \mathrm{CI}: .00$ to .09), while the indirect effect was only marginally significant for male participants $\left(b_{\text {male }}=.03, S E=.02, p=.09 ; 95 \% \mathrm{CI}\right.$ : -.00 to .07$)$. In contrast, the feminine traits - LOC-challenge appraisals indirect effect was not significant $\left(b_{\text {female }}=.01, S E=.02, p=.60\right)$.

Third, in models predicting threat appraisals, masculine traits were negatively related to threat appraisals in both male (H3: $\left.b_{\text {male }}=-.25, S E=.08, p=.004\right)$ and female participants $\left(\mathrm{H} 3: b_{\text {female }}=-.43, S E=.09, p<.001\right)$. Feminine traits were marginally related to increased threat appraisals, but in male participants only $\left(\mathrm{H} 9: b_{\text {male }}=.14\right.$,
$\left.S E=.08, p=.07 ; b_{\text {female }}=.07, S E=.09, p=.44\right)$. Then, LOC was entered in the model: In both male and female participants it was significantly related to lower levels of threat appraisals (H5; see the two right panels of Table 3). The bootstrapped masculine traits - LOC - threat appraisal indirect path (H7) was marginally significant for both male $\left(b_{\text {male }}=-.05, S E=.03, p=.08 ; 95 \% \mathrm{CI}:-.11\right.$ to .01$)$ and female participants $\left(b_{\text {female }}=-.06, S E=.06, p=.06\right.$; $95 \% \mathrm{CI}$ : -.13 to .00$)$. In addition, as feminine traits were related to LOC among male participants, we tested for a feminine traits - LOC - threat appraisals indirect path: It was not significant $\left(b_{\text {male }}=-.03, S E=.02, p=.24\right)$.

Finally, it should be noted that, again, control variables had no significant impact on LOC, challenge appraisals, and threat appraisals.

\section{Discussion}

The present study provided a timely account of the relationships between gender traits and the way students living in the French-speaking region of Switzerland appraise events in their everyday life. As expected, masculine traits were closely related to appraisals of events as challenges, and a high internal/low external locus of control was consistently found to mediate this relationship. Masculine traits also decreased threat appraisals, through a low internal/high external locus of control, but this effect appeared to be stronger in female students. The results regarding feminine traits revealed a more complex pattern. First, the impact of feminine traits on gender traits was less pronounced, and differed across genders. Moreover, and in line with previous research (in non-student US adults, Kapalka and Lachenmeyer 1988; in US undergraduates, Lengua and Stormshak 2000), feminine traits were not related to the locus of control adopted by young adults. Overall, the present results call for a deeper discussion about the different dynamics underlying masculine and feminine traits, the meaning of their expression by male and female young adults, and their concrete consequences in terms of 
well-being and stress management. We conclude by discussing both the limitations of the present study and to what extent our findings, obtained in two student samples from the French-speaking part of Switzerland, apply to other populations.

\section{Masculinity, Internal Control, and Well-being}

The present study confirmed and extended past research on gender traits by showing that male and female students with masculine traits tended to appraise events as challenges. To a lesser extent, masculine traits were also related to decreased threat appraisals. Finally, and as expected, believing that one can control events in one's own life was found to underlie the influence of masculine traits on cognitive appraisals.

These findings contribute to understanding why masculinity, problem-focused coping strategies (i.e., aimed at changing or removing the stressor), and increased well-being often go hand in hand. Indeed, masculine traits have been related to a higher ability to identify solutions to everyday issues (social problem-solving in US college students; Wang 2007), to lower psychological distress (in Hong Kong university students, Lam and McBride-Chang 2007) and, generally, to increased well-being (for a meta-analysis see Whitley 1985). In turn, challenge appraisals were found to be related to problem-focused coping strategies (in US undergraduates, Ptacek et al. 1992), higher performance (in Israeli undergraduates, Drach-Zahavy and Erez 2002), and lower subjective stress (in US college students, Tomaka et al. 1993). Based on the findings of the present study, future research may consider challenge appraisals as a way to bridge the study of masculine traits and well-being outcomes.

\section{Femininity: A More Complex Pattern of Results}

The potential implications of our findings in terms of wellbeing are less clear-cut when it comes to femininity. Feminine traits had mostly an impact on threat appraisals and, with one exception, did not relate to challenge appraisals. Furthermore, and in line with previous findings, feminine traits were not related to locus of control.

First, the fact that feminine traits were more strongly related to threat appraisals than to challenge appraisals suggests that different mechanisms may underlie the two types of cognitive appraisals. Since we had no firm reason to expect differences, we hypothesized reverse effects for challenge and threat appraisals (that is, if a factor was predicted to relate to increased challenge appraisals, we also predicted it to relate to decreased threat appraisals). This appeared to be true for masculine traits, which were related, through a high internal/ low external locus of control, to both higher scores of challenge appraisals and lower scores of threat appraisals. This lends credence to our assumption that the sense of mastery over events reflected in masculine traits (e.g., dominant, willing to take risks) explains how masculine young adults perceive events in their everyday life. In contrast, femininity was related to threat appraisals mostly, which may be explained by the content of feminine traits. Indeed, because femininity is characterized by the expression of feelings and emotions, individuals with feminine traits appeared to acknowledge more easily that they perceived events as threatening. Quite the contrary, there is nothing to acknowledge when one says that they perceive events as challenges. This may be the reason behind the lack of or weak relationship between feminine traits and challenge appraisals.

Second, the absence of relationship between feminine traits and locus of control may be due to the nature of the perceived control we examined. Indeed, as we did in the present study, perceived control is usually evaluated as being general control over events. However, scales addressing specific domains, such as affiliation, that is the closeness or identification with other individuals, have also been developed (Lefcourt et al. 1979). While men traditionally tended to be more internal (Sherman et al. 1997), they were also found to attribute affiliation to external sources to a greater extent than women (Lefcourt et al. 1979). Thus, feminine traits might relate to cognitive appraisal through affiliation LOC; as women tend to be more feminine than men, feminine traits can be expected to relate to the belief that one controls the extent to which one is close to others (e.g., that one is able to integrate in a social group), which, in turn, may lead to the perception of social situations as challenging, and not as threatening.

\section{Limitations and Future Research}

The present study suffers from several limitations that need to be discussed. First, since we relied on correlational data from self-report questionnaires, future research using experimental designs is needed to replicate the mechanisms found in the present study. For instance, young adults could be confronted by fictional stressful situations. Based on the results of the present study, those with strong masculine traits and a high internal/low external locus of control should report fewer physiological and psychological symptoms of stress when faced by these fictional situations. Second, the extent to which our findings have the potential to contribute to the understanding of the relationships between gender traits and cognitive appraisals beyond student populations needs to be addressed. Indeed, not only were the participants of the present study young, but they were also in higher education, where less pronounced gender differences in gender traits are generally found (e.g., in Spain, Calvo-Salguero et al. 2008). Thus, in the same context (i.e., the French-speaking region of Switzerland), not only older individuals but also young adults with lower levels of education (and thus presumably already in the labor market) very likely express more gender 
stereotypical traits (e.g., men would express more masculine traits). Whether this would also result in stronger relationships to cognitive appraisals is an empirical question that should be addressed in future studies.

Finally, Switzerland can be described as a Western society where not only rather traditional gender roles are still prevalent but also masculine agentic traits are generally valued. In such a context, the impact of expressing masculine traits, both in men and women, may be emphasized. To test such assumptions, future research should compare the interplay between gender traits, perceived control, and cognitive appraisals across cultures and countries with different levels of gender equality and prevailing gender roles (for an overview of national-level operationalization of such concepts, see ElseQuest and Grabe 2012). Similar examinations could also be carried out at a more proximal level. For instance, future studies could also examine whether the expression of gender traits impact similarly male and female students in traditionally feminine fields (e.g., nursing) of study as students in traditionally masculine fields (e.g., engineering).

\section{Conclusion}

Overall, the present study confirmed that, in a context such as Switzerland, stereotypical gender traits are key to understanding how young adults appraise events in their everyday lives. Especially masculine traits, through the belief that one controls the events that affect individuals' life, predict cognitive appraisals, which, in turn, are known to have positive impact on well-being outcomes. In contrast, in light of the present study's results, it appears that distinctions between domains should be made to further understand how feminine traits are related to cognitive appraisal, coping strategies, and wellbeing in general. Finally, future research should address how the expression of gender traits by young adults interacts with prevailing gender ideologies to predict well-being and stressrelated outcomes.

\section{References}

Auster, C. J., \& Ohm, S. C. (2000). Masculinity and femininity in contemporary American society: A reevaluation using the Bem Sex-Role Inventory. Sex Roles, 43, 499-528. doi:10.1023/ A:1007119516728.

Baron, R. M., \& Kenny, D. A. (1986). The moderator-mediator variable distinction in social psychological research: Conceptual, strategic, and statistical considerations. Journal of Personality and Social Psychology, 51, 1173-1182. doi:10.1037/0022-3514.51.6.1173.

Bassoff, E. S., \& Glass, G. V. (1982). The relationship between sex roles and mental health: A meta-analysis of twenty-six studies. The Counseling Psychologist, 10, 105-112. doi:10.1177/ 0011000082104019.
Bem, S. L. (1974). The measurement of psychological androgyny. Journal of Consulting and Clinical Psychology, 42, 155-162. doi: $10.1037 / \mathrm{h} 0036215$.

Bem, S. L. (1975). Sex role adaptability: One consequence of psychological androgyny. Journal of Personality and Social Psychology, 31, 634-643. doi:10.1037/h0077098.

Bem, S. L. (1981). Gender schema theory: A cognitive account of sex typing. Psychological Review, 88, 354-364. doi:10.1037/0033295X.88.4.354.

Berjot, S., \& Girault-Lidvan, N. (2009). Validation d'une version française de l'échelle d'évaluation cognitive primaire de Brewer et Skinner [Validation of a French version of the Cognitive Appraisal Scale (Trait) by Brewer and Skinner]. Canadian Journal of Behavioural Science, 41, 252-259. doi:10.1037/a0014842.

Bernardi, R. A. (1997). The relationships among locus of control, perceptions of stress and performance. Journal of Applied Business Research, 13, 1-8.

Biernat, M., \& Deaux, K. (2012). A history of social psychological research on gender. In A. W. Kruglanski \& W. Stroebe (Eds.), Handbook of the history of social psychology (pp. 475-498). New York: Psychology Press.

Bouvard, M. (2009). Questionnaires et échelles d'évaluation de la personnalité (3ème édition) [Personality scales and questionnaires, 3rd ed.]. Paris: Elsevier Masson.

Branger, K., Gazareth, P., \& Schön-Bühlmann, J. (2003). Données sociales-Suisse. Vers l'égalité? La situation des femmes et des hommes en Suisse, Troisième rapport statistique [Social DataSwitzerland. Toward equality? The situation of women and men in Switzerland, third statistical report]. Neuchâtel: Swiss Federal Statistical Office.

Bronstein, P., Briones, M., Brooks, T., \& Cowan, B. (1996). Gender and family factors as predictors of late adolescent emotional expressiveness and adjustment: a longitudinal study. Sex Roles, 34, 739-765. doi:10.1007/BF01544314.

Calvo-Salguero, A., García-Martínez, J. M. A., \& Monteoliva, A. (2008). Differences between and within genders in gender role orientation according to age and level of education. Sex Roles, 58, 535-548. doi:10.1007/s11199-007-9354-6.

Cattell, R. B. (1966). The screen test for the number of factors. Multivariate Behavioral Research, 1, 245-276. doi:10.1207/ s15327906mbr0102_10.

Cheng, C. (2005). Processes underlying gender-role flexibility: Do androgynous individuals know more or know how to cope? Journal of Personality, 73, 645-673. doi:10.1111/j.1467-6494.2005.00324.x.

Christopher, A. N., Saliba, L., \& Deadmarsh, E. J. (2009). Materialism and well-being: The mediating effect of locus of control. Personality and Individual Differences, 46, 682-686. doi:10.1016/j.paid.2009. 01.003 .

Colley, A., Mulhern, G., Maltby, J., \& Wood, A. M. (2009). The short form BSRI: Instrumentality, expressiveness and gender associations among a United Kingdom sample. Personality and Individual Differences, 46, 384-387. doi:10.1016/j.paid.2008.11.005.

Costa, P. T., Jr., Terracciano, A., \& McCrae, R. R. (2001). Gender differences in personality traits across cultures: Robust and surprising findings. Journal of Personality and Social Psychology, 81, 322-331. doi:10.1037/0022-3514.81.2.322.

Costello, A. B., \& Osborne, J. W. (2005). Best practices in exploratory factor analysis: Four recommendations for getting the most from your analysis. Practical Assessment, Research \& Evaluation, 10, 19.

Drach-Zahavy, A., \& Erez, M. (2002). Challenge versus threat effects on the goal-performance relationship. Organizational Behavior and Human Decision Processes, 88, 667-682. doi:10.1016/S07495978(02)00004-3.

Else-Quest, N. M., \& Grabe, S. (2012). The political is personal: Measurement and application of nation-level indicators of gender 
equity in psychological research. Psychology of Women Quarterly, 36, 131-144. doi:10.1177/0361684312441592.

Feingold, A. (1994). Gender differences in personality: A meta-analysis. Psychological Bulletin, 116, 429-456. doi:10.1037/0033-2909.116. 3.429.

Fontayne, P., Sarrazin, P., \& Famose, J.-P. (2000). The Bem Sex-Role inventory: Validation of a short version for French teenagers. European Review of Applied Psychology, 50, 405-416.

Gianakos, I. (2002). Predictors of coping with work stress: The influences of sex, gender role, social desirability, and locus of control. Sex Roles, 46, 149-158. doi:10.1023/A:1019675218338.

Guimond, S., Dambrun, M., Michinov, N., \& Duarte, S. (2003). Does social dominance generate prejudice? Integrating individual and contextual determinants of intergroup cognitions. Journal of Personality and Social Psychology, 84, 697-721. doi:10.1037/ 0022-3514.84.4.697.

Hofstede, G. (2001). Culture's consequences: Comparing values, behaviors, institutions, and organizations across nations. Thousand Oaks: Sage.

Judge, T. A., Erez, A., Bono, J. E., \& Thoresen, C. J. (2002). Are measures of self-esteem, neuroticism, locus of control, and generalized self-efficacy indicators of a common core construct? Journal of Personality and Social Psychology, 83, 693-710. doi:10.1037/ 0022-3514.83.3.693.

Kapalka, G. M., \& Lachenmeyer, J. R. (1988). Sex-role flexibility, locus of control, and occupational status. Sex Roles, 19, 417-427. doi:10. 1007/BF00289716.

Lam, C. B., \& McBride-Chang, C. A. (2007). Resilience in young adulthood: The moderating influences of gender-related personality traits and coping flexibility. Sex Roles, 56, 159-172. doi:10.1007/ s11199-006-9159-z.

Lazarus, R. S. (1966). Psychological stress and the coping process. New York: McGraw-Hill.

Lazarus, R. S. (1991). Emotion and adaptation. New York: Oxford University Press.

Lazarus, R. S. (2006). Stress and emotion: A new synthesis. New York: Springer.

Lazarus, R. S., \& Folkman, S. (1984). Stress, appraisal, and coping. New York: Springer.

Lefcourt, H. M. (1982). Locus of control: Current trends in theory and research (2nd ed.). Hillsdale: Erlbaum.

Lefcourt, H. M., von Baeyer, C. L., Ware, E. E., \& Cox, D. J. (1979). The multidimensional-multiattributional causality scale: The development of a goal specific locus of control scale. Canadian Journal of Behavioural Science, 11, 286-304. doi:10.1037/h0081598.

Lengua, L. J., \& Stormshak, E. A. (2000). Gender, gender roles, and personality: Gender differences in the prediction of coping and psychological symptoms. Sex Roles, 43, 787-820. doi:10.1023/ A:1011096604861.

Leung, C., \& Moore, S. (2003). Individual and cultural gender roles: A comparison of Anglo-Australians and Chinese in Australia. Current Research in Social Psychology, 8, 302-316.

Levenson, H. (1974). Activism and powerful others: Distinctions within the concept of internal-external control. Journal of Personality Assessment, 38, 377-383. doi:10.1080/00223891.1974.10119988.

Levenson, H. (1981). Differentiating among internality, powerful others, and chance. In H. M. Lefcourt (Ed.), Research with the locus of control construct (Vol. 1, pp. 15-63). New York: Academic Press.

Loas, G., Dardennes, R., Dhee-Perot, P., Leclerc, V., \& Fremaux, D. (1994). Opérationnalisation du concept de" lieu de contrôle": Traduction et première étude de validation de l'échelle de contrôle de Levenson (IPC: the internal, powerful others, and chance scale) [Locus of control: Initial validation of a French translation of Levenson's IPC Scale]. Annales Médico-Psychologiques, 152, 466-469.
Long, B. C., Kahn, S. E., \& Schutz, R. W. (1992). Causal model of stress and coping: Women in management. Journal of Counseling Psychology, 39, 227-239. doi:10.1037/0022-0167.39.2.227.

Losa, F. B., \& Origoni, P. (2005). The socio-cultural dimension of women's labour force participation choices in Switzerland. International Labour Review, 144, 473-494. doi:10.1111/j.1564913X.2005.tb00578.x.

Mak, A. S., Blewitt, K., \& Heaven, P. C. (2004). Gender and personality influences in adolescent threat and challenge appraisals and depressive symptoms. Personality and Individual Differences, 36, 14831496. doi:10.1016/S0191-8869(03)00243-5.

Martínez, C., Paterna, C., Roux, P., \& Falomir, J. M. (2010). Predicting gender awareness: The relevance of neo-sexism. Journal of Gender Studies, 19, 1-12. doi:10.1080/09589230903057142.

Moore, D. (2007). Self perceptions and social misconceptions: The implications of gender traits for locus of control and life satisfaction. Sex Roles, 56, 767-780. doi:10.1007/s11199-0079238-9.

Moya, M., Poeschl, G., Glick, P., Paez, D., \& Fernandez Sedano, I. (2005). Sexisme, masculinité-féminité et facteurs culturels [Sexism, masculinity-feminity and cultural factors]. Revue Internationale de Psychologie Sociale, 18, 141-167.

Ng, T. W. H., Sorensen, K. L., \& Eby, L. T. (2006). Locus of control at work: A meta-analysis. Journal of Organizational Behavior, 27, 1057-1087. doi:10.1002/job.416.

O'brien, R. M. (2007). A caution regarding rules of thumb for variance inflation factors. Quality \& Quantity, 41, 673-690. doi:10.1007/ s11135-006-9018-6.

Özkan, T., \& Lajunen, T. (2005). Masculinity, femininity, and the Bem Sex Role inventory in Turkey. Sex Roles, 52, 103-110. doi:10.1007/ s11199-005-1197-4.

Preacher, K. J., \& Hayes, A. F. (2004). SPSS and SAS procedures for estimating indirect effects in simple mediation models. Behavior Research Methods, Instruments, \& Computers, 36, 717-731. doi: 10.3758/BF03206553.

Ptacek, J. T., Smith, R. E., \& Zanas, J. (1992). Gender, appraisal, and coping: A longitudinal analysis. Journal of Personality, 60, 747770. doi:10.1111/j.1467-6494.1992.tb00272.x.

Ridgeway, C. L. (2011). Framed by gender: How gender inequality persists in the modern world. New York: Oxford University Press.

Roddenberry, A., \& Renk, K. (2010). Locus of control and self-efficacy: Potential mediators of stress, illness, and utilization of health services in college students. Child Psychiatry \& Human Development, 41, 353-370. doi:10.1007/s10578-010-0173-6.

Roesch, S. C., \& Rowley, A. A. (2005). Evaluating and developing a multidimensional, dispositional measure of appraisal. Journal of Personality Assessment, 85, 188-196. doi:10.1207/ s15327752jpa8502_11.

Rossier, J., Rigozzi, C., \& Berthoud, S. (2002). Validation de la version française de l'échelle de contrôle de Levenson (IPC), influence de variables démographiques et de la personnalité [Validation of the French translation of the Levenson's locus of control scale (IPC). Influence of demographic variables and personality]. Annales Médico-Psychologiques, 160, 138-148. doi:10.1016/S00034487(01)00111-1.

Rotter, J. B. (1966). Generalized expectancies for internal versus external control of reinforcement. Psychological Monographs: General and Applied, 80, 1-28. doi:10.1037/h0092976.

Sarason, I. G., \& Sarason, B. R. (1990). Test anxiety. In H. Leitenbert (Ed.), Handbook of social and evaluation anxiety (pp. 475-495). New York: Plenum Press.

Seery, M. D., Blascovich, J., Weisbuch, M., \& Vick, S. B. (2004). The relationship between self-esteem level, self-esteem stability, and cardiovascular reactions to performance feedback. Journal of Personality and Social Psychology, 87, 133-145. doi:10.1037/ 0022-3514.87.1.133. 
Sherman, A. C., Higgs, G. E., \& Williams, R. L. (1997). Gender differences in the locus of control construct. Psychology \& Health, 12, 239-248. doi:10.1080/08870449708407402.

Sigmon, S. T., Stanton, A. L., \& Snyder, C. R. (1995). Gender differences in coping: A further test of socialization and role constraint theories. Sex Roles, 33, 565-587. doi:10.1007/BF01547718.

Skinner, N., \& Brewer, N. (2002). The dynamics of threat and challenge appraisals prior to stressful achievement events. Journal of Personality and Social Psychology, 83, 678-692. doi:10.1037// 0022-3514.83.3.678.

Snedker, K. A. (2006). Altruistic and vicarious fear of crime: Fear for others and gendered social roles. Sociological Forum, 21, 163-195. doi:10.1007/s11206-006-901.

Snellman, A., Ekehammar, B., \& Akrami, N. (2009). The role of gender identification in social dominance orientation: Mediating or moderating the effect of sex? Journal of Applied Social Psychology, 39, 999-1012. doi:10.1111/j.1559-1816.2009.00469.x.

Stake, J. E. (2000). When situations call for instrumentality and expressiveness: Resource appraisal, coping, strategy choice, and adjustment. Sex Roles, 42, 865-885. doi:10.1023/A:1007098400593.

StataCorp. (2011). Stata Statistical Software: Release 12. College Station: StataCorp LP.

Tomaka, J., Blascovich, J., Kelsey, R. M., \& Leitten, C. L. (1993). Subjective, physiological, and behavioral effects of threat and challenge appraisal. Journal of Personality and Social Psychology, 65, 248-260. doi:10.1037/0022-3514.65.2.248.

Tomaka, J., Palacios, R., Schneider, K. T., Colotla, M., Concha, J. B., \& Herrald, M. M. (1999). Assertiveness predicts threat and challenge reactions to potential stress among women. Journal of Personality and Social Psychology, 76, 1008-1021. doi:10.1037/0022-3514.76. 6.1008 .

Twenge, J. M. (1997). Change in masculine and feminine traits over time: A meta-analysis. Sex Roles, 36, 305-325. doi:10.1007/BF02766650.
Twenge, J. M. (2009). Status and gender: The paradox of progress in an age of narcissism. Sex Roles, 61, 338-340. doi:10.1007/s11199-009-9617-5.

Twenge, J. M., Zhang, L., \& Im, C. (2004). It's beyond my control: A cross-temporal meta-analysis of increasing externality in locus of control, 1960-2002. Personality and Social Psychology Review, 8, 308-319. doi:10.1207/s15327957pspr0803 5.

Vitaliano, P. P., Russo, J., \& Maiuro, R. D. (1987). Locus of control, type of stressor, and appraisal within a cognitive-phenomenological model of stress. Journal of Research in Personality, 21, 224-237. doi: 10.1016/0092-6566(87)90009-2.

Wagner-Egger, P., \& Bangerter, A. (2008). La vérité est ailleurs: Corrélats de l'adhésion aux théories du complot [The truth lies elsewhere: Correlates of belief in conspiracy theories]. Revue Internationale de Psychologie Sociale, 4, 31-61.

Wang, X. (2007). A model of the relationship of sex-role orientation to social problem-solving. Sex Roles, 57, 397-408. doi:10.1007/ s11199-007-9285-2.

Whitley, B. E. (1985). Sex-role orientation and psychological well-being: Two meta-analyses. Sex Roles, 12, 207-225. doi:10.1007/ BF00288048.

Wilkinson, W. W. (2007). The structure of the Levenson locus of control scale in young adults: Comparing item and parcel indicator models. Personality and Individual Differences, 43, 1416-1425. doi:10. 1016/j.paid.2007.04.018.

Williams, J. M., \& Stout, J. K. (1985). The effect of high and low assertiveness on locus of control and health problems. Journal of Psychology: Interdisciplinary and Applied, 119, 169-173.

Woodhill, B. M., \& Samuels, C. A. (2003). Positive and negative androgyny and their relationship with psychological health and well-being. Sex Roles, 48, 555-565. doi:10.1023/A:1023531530272.

Yaremko, S. K., \& Lawson, K. L. (2007). Gender, internalization of expressive traits, and expectations of parenting. Sex Roles, 57, 675-687. doi:10.1007/s11199-007-9301-6. 